\title{
Avaliação do atendimento às mulheres vítimas de violências sexual no CAISM/UNICAMP no período de 2012 a 2017.
}

\section{Caroline A Duarte*, Arlete Maria dos S Fernandes.}

\begin{abstract}
Resumo
Dentre os tipos de violência, os abusos sexuais são os que mais afetam as mulheres, tendo os homens como agentes mais frequentes do delito.Objetivos: Essa pesquisa teve por objetivo conhecer e caracterizar as mulheres que procuraram o serviço especializado do CAISM/UNICAMP e avaliar a qualidade de cuidado prestado pelo serviço. Sujeitos e Método: Um estudo retrospectivo com levantamento dos 887 casos do banco de dados do atendimento às vítimas de violência nos últimos seis anos e com complementação de alguns dados a partir da revisão de prontuários médicos. Resultados: é necessário buscar estratégia mais eficientes na convocação e adesão dessas pacientes ao atendimento disponível
\end{abstract}

Palavras-chave: violência sexual, profilaxia e agravos.

\section{Introdução}

A violência é definida, pela Organização Mundial de Saúde (OMS), como o uso de força física ou de poder, sobre forma de ameaça ou real, que resulte ou possa levar a lesão, morte ou dano psicológico, prejuízos ao desenvolvimento ou privação a si próprio, a outra pessoa ou comunidade Essa problemática é mundial e foi definida como um problema de saúde pública, ainda segundo a OMS, uma em cada três mulheres já sofreram violência sexual, tendo uma incidência de doze milhões de vítimas por ano. Os prejuízos que uma violência sexual causa à vítima podem ser a longo ou curto prazo, abrangendo várias esferas da saúde da mulher, como física, psíquica e social. Pelo potencial de complicações e agravos, após um evento violento tem sido preconizado o atendimento inicial na área da saúde. ${ }^{1}$

No CAISM esse serviço foi iniciado em 1994 com atendimento de emergência e normatizado com acompanhamento ambulatorial nos primeiros seis meses, com equipe multidisciplinar, a partir de 1998 sob o nome de Serviço de Atendimento Especial. Portanto essa pesquisa tem por objetivo conhecer e caracterizar as mulheres que procuraram o serviço especializado do Hospital da Mulher Prof. Dr. José Aristodemo Pinotti da Universidade Estadual de Campinas e a tipologia da violência sofrida, além de avaliar a qualidade de cuidado prestado pelo serviço.

\section{Resultados e Discussão}

Foram levantados dados de 887 atendimentos realizados no período de 2012 a 2017, através do banco online preenchido pelos profissionais durante a prestação do serviço, além disso já foi realizada a complementação de informações de 665 desses atendimentos nos prontuários físicos resguardados ao CAISM/UNICAMP. Das mulheres que receberam esses atendimentos $65 \%$ se autodeclararam brancas, $26 \%$ pardas e $7 \%$ pretas, encontrando-se em estado civil casada $75 \%$ delas. Das condições relacionadas a violência em $1 / 4$ dos casos a abordagem aconteceu dentro da residência da própria vítima e $40 \%$ dos casos foram atribuídos a agressores conhecidos por elas. Na pesquisa de complementação não obtivemos dados relevantes na relação entre os casos de violências sexual e a interferência das mídias sociais, pois em $92 \%$ as ocorrências com agressores conhecidos a aproximação foi pessoalmente.

No atendimento inicial de emergência $70 \%$ das mulheres receberam como profilaxia para infecção por HIV, o esquema BIOVIR+KALETRA, porém o uso correto por 28 dias foi identificado em apenas $44 \%$ delas, $12 \%$ interromperam o tratamento, sendo o maior motivo a intolerância à medicação. Ressalto que nos demais $43 \%$ dos casos não havia informação no prontuário referente ao uso correto e término dessas medicações. Em relação a profilaxia contra infecção pelo vírus HBV, a vacina e imunoglobulina são aplicadas na emergência, além de uma orientação para complementação das duas doses restantes da vacina ou confirmação dessas pela carteira de vacinação. Porém em $68 \%$ dos casos revistos não encontramos nenhum registro em prontuário verificando essa informação, apenas $17 \%$ das mulheres atendidas comprovaram vacinação e as demais $15 \%$ apresentaram carteira de vacinação incompleta.

O tempo adequado entre a agressão e a realização das profilaxias contra infecção e gestação é de 72 horas, para sua maior efetividade. No serviço prestado pelo ambulatório identificamos que $91 \%$ das pacientes procuram ou são trazidas antes desse horário limite, porém apenas metade delas seguem o atendimento de 6 meses até receberem a alta, sendo que entre essas que descontinuam $59 \%$ apenas realizam o atendimento de emergência e nenhuma consulta no ambulatório.

\section{Conclusões}

Os resultados evidenciam uma importante vivência de violência sexual das mulheres por agressores de seu convívio, bem como em ambientes habituais de sua rotina, consequência direta da desigualdade de gênero. O serviço avaliado dispensa às pacientes todas as profilaxias previstas pelo ministério da saúde e atendimento multidisciplinar, porém ainda é necessário buscar estratégia mais eficientes na convocação e adesão dessas pacientes ao atendimento disponível, bem como compreender as razões existentes para evasão.

1 Faúndes A, et al. Violência sexual: procedimentos indicados e seus resultados no atendimento de urgência de mulheres vítimas de estupro. Rev Bras Ginecol Obstet. 2006; 28(2): 126-35 